\title{
KRAB zinc-finger protein 382 regulates epithelial-mesenchymal transition and functions as a tumor suppressor, but is silenced by $\mathrm{CpG}$ methylation in gastric cancer
}

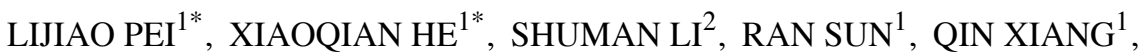 \\ GUOSHENG REN ${ }^{1}$ and TINGXIU XIANG ${ }^{1}$ \\ ${ }^{1}$ Chongqing Key Laboratory of Molecular Oncology and Epigenetics, \\ The First Affiliated Hospital of Chongqing Medical University, Chongqing 400016; ${ }^{2}$ Department of Oncology, \\ The Second Affiliated Hospital of Chongqing Medical University, Chongqing 400010, P.R. China
}

Received February 2, 2018; Accepted June 7, 2018

DOI: $10.3892 /$ ijo.2018.4446

\begin{abstract}
Several studies have recently reported that KRAB zinc finger protein 382 (ZNF382) is downregulated in multiple carcinoma types due to promoter methylation. The exact role of ZNF382 in gastric carcinogenesis, however, remains elusive. In this study, we investigated the alterations and functions of ZNF382 in the pathogenesis of gastric cancer (GC). Semi-quantitative reverse transcription-polymerase chain reaction (RT-PCR), quantitative (real-time) PCR (qPCR) and immunohistochemistry were carried out to detect the expression patterns of ZNF382 in GC cell lines and gastric tissue samples. Furthermore, its methylation status in GC cell lines, tumor tissues and adjacent non-tumor tissues was detected by methylation-specific PCR (MSP). We observed that ZNF382 was silenced due to promoter methylation in MKN45 and SGC7901 cell lines, and that its silencing could be reversed with 5-aza-2'-deoxycytidine, indicating that its downregulation in GC is due to promoter methylation. In addition, the ectopic expression of ZNF382 significantly inhibited gastric tumor cell clonogenicity, proliferation, migration and epithelial-mesenchymal transition (EMT) through the induction of apoptosis. ZNF382 expression downregulated the expression of SNAIL, Vimentin, Twist, NOTCH1, NOTCH2, NOTCH3, NOTCH4, HES-1, JAG1, matrix metalloproteinase (MMP)2 and $M M P 11$, as well as that of the stem cell markers, NANOG, octamer-binding transcription factor 4 (OCT4) and SOX2.
\end{abstract}

Correspondence to: Professor Tingxiu Xiang, Chongqing Key Laboratory of Molecular Oncology and Epigenetics, The First Affiliated Hospital of Chongqing Medical University, 1 Yixueyuan Road, Chongqing 400016, P.R. China

E-mail: larissaxiang@163.com

${ }^{*}$ Contributed equally

Key words: KRAB zinc-finger protein 382, tumor suppressor, gastric cancer, epithelial-mesenchymal transition, NOTCH pathway
ZNF382 also upregulated the expression of E-cadherin. On the whole, the findings of this study suggest that ZNF382 functions as a tumor suppressor in GC cells, but is frequently methylated in both GC cell lines and primary gastric tumors. ZNF382 can reverse the EMT process in GC cells through $\mathrm{NOTCH}$ signaling. Our findings further illustrate the molecular pathogenesis of GC and establish potential biomarkers for this type of cancer.

\section{Introduction}

Gastric cancer (GC) is currently the fourth most common malignancy in the worldwide scale. It remains the second leading cause of cancer-related mortality, with a poor prognosis following diagnosis. Regrettably, a large proportion of patients with GC are at a late stage when diagnosed due to a lack of effective screening programs (1-3). Zinc finger proteins (ZFPs) comprise one of the largest transcription factor families and are found exclusively in tetrapod vertebrates (4). The Krüppel-associated box (KRAB) exists in approximately one-third of ZFPs (4). KRAB-ZFPs are considered crucial regulators of diverse cellular progresses, such as cell differentiation, proliferation, apoptosis and tumorigenesis (4-6). ZFPs can activate or suppress gene expression by binding to promoters $(7,8)$. The ZNF382 gene, a novel zinc finger transcription factor described previously, is located on chromosome 19 q13.12 and contains only one KRAB domain. It has been shown to be a tumor suppressor gene (TSG) and is commonly downregulated due to the hypermethylation of its promoter CpG island in multiple carcinomas, including GC $(4,9)$. Moreover, ZNF382 can inhibit activator protein-1 (AP-1) and nuclear factor (NF)- $\kappa \mathrm{B}$ signaling and downregulate multiple oncogenes, including melanogenesis associated transcription factor $(M I T F), \mathrm{MYC}$, cyclin dependent kinase $(C D K) 6$ and high mobility group AT-hook 2 (HMGA2), and it can also downregulate several upstream factors of $\mathrm{NF}-\kappa \mathrm{B}$, including signal transducer and activator of transcription (STAT)3, STAT5B and inhibitor of DNA binding 1, HLH protein (IDI) (9).

Epithelial-mesenchymal transition (EMT) is both a physiological and pathological course, regulating cell phenotype 
and function during normal development and tumor development (including GC) (10-12). Previous studies have verified the vital role of $S N A I L$ in suppressing E-cadherin expression; SNAIL downregulates the expression of E-cadherin by binding to the two E-boxes of the E-cadherin promoter (13). Reportedly, various signaling pathways, including NF-кB, Wnt and NOTCH, are involved in this multi-step event $(14,15)$. Notably, NOTCH has been identified as a key factor involved in tumor metastasis (16-18).

As there are limited studies available on ZNF382, at least to the best of our knowledge, its roles during EMT and GC are unclear. Thus, in this study, in order to clarify the role of ZNF382 in GC, the expression level and the methylation status of its promoter in GC cell lines and paired gastric tumor tissues were examined. We further examined its biological function and the potential underlying molecular mechanisms involved in gastric tumorigenesis.

\section{Materials and methods}

Cell culture and tissue samples. Five GC cell lines (AGS, BGC823, MKN28, MKN45 and SGC7901) were used. The AGS, MKN28 (reported to be a derivative of the MKN74 GC cell line) $(19,20)$ and MKN45 cells were acquired from the American Type Culture Collection (ATCC; Manassas, VA, USA) or provided by Professor Qian Tao (the Chinese University of Hong Kong, Hong Kong, China). The BGC823 and SGC7901 cells were purchased from the Cell Resource Center of Shanghai Institution for Biological Sciences, Chinese Academy of Sciences (Shanghai, China). The cells were allowed to grown in RPMI-1640 medium (Gibco-BRL, Karlsruhe, Germany) at $37^{\circ} \mathrm{C} / 5 \% \mathrm{CO}_{2}$, supplemented with $100 \mathrm{mg} / \mathrm{ml}$ streptomycin, $100 \mathrm{U} / \mathrm{ml}$ penicillin and $10 \%$ fetal bovine serum (FBS; PAA Laboratories, Linz, Austria). The MKN45 and SGC7901 cell lines which were transfected with pcDNA3.1-ZNF382-Flag or vector pcDNA3.1 were selected with geneticin (G418). The ectopic expression of ZNF382 was assayed by RT-PCR and western blot analysis prior to the other experimental procedures. A total of 5 normal gastric tissues, 138 primary gastric tumor tissues and 64 matched adjacent non-tumor tissue samples were acquired from the First Affiliated Hospital of Chongqing Medical University, Chongqing, China (January, 2012 to November, 2016). Clinical and pathological information was collected for the majority of the tumor samples. DNA and RNA extraction for the majority of these tissue samples were performed. This study was approved by the Ethics Committee of the First Affiliated Hospital of Chongqing Medical University, and all patients provided signed informed consent.

DNA and RNA extraction. The QIAamp ${ }^{\circledR}$ DNA Mini kit (Qiagen, Hilden, Germany) was used for the genomic DNA extraction from the cell lines and tissues in accordance with the manufacturer's instructions. TRIzol ${ }^{\circledR}$ reagent (Invitrogen; Thermo Fisher Scientific, Inc., Waltham, MA, USA) was used for the total RNA isolation from the cell lines and tissue samples $\left(-80^{\circ} \mathrm{C}\right.$ for sample storage).

Semi-quantitative reverse transcription- $P C R(R T-P C R)$ and quantitative PCR (qPCR). Briefly, the RNA (1 $\mu \mathrm{g})$ to $20 \mu \mathrm{g}$ of
cDNA, the Reverse Transcription system (Promega, Madison, WI, USA) was used. RT-PCR was carried out as previously described (21). GAPDH was used as an internal control. RT-PCR was performed ( 32 cycles for target genes, 23 cycles for $G A P D H$ ) with Go-Taq polymerase (Promega). qPCR was carried out in accordance with the instructions of the ABI 7500 system (Applied Biosystems, Foster City, CA, USA) using SYBR ${ }^{\circledR}$-Green qPCR Master Mix (MBI Fermentas, St. Leon-Rot, Germany). The primers used in this study are listed in Table I.

5-Aza-2'-deoxycytidine (Aza) and trichostatin A (TSA) treatment.Fresh medium containing $10 \mathrm{mmol} / 1$ Aza (Sigma-Aldrich, Steinheim, Germany) was used for cell culture. After 3 days, the cells were treated with $100 \mathrm{nmol} / 1 \mathrm{TSA}$ (Sigma-Aldrich) for the following $24 \mathrm{~h}$. Cells were then collected for RNA extraction (22).

DNA bisulfite treatment and methylation-specific PCR (MSP). DNA bisulfite modifications and MSPs were carried out in accordance with previously described methods $(23,24)$. The primers used for MSP are listed in Table I. AmpliTaq ${ }^{\circledR}$-Gold DNA Polymerase (Applied Biosystems) was used, and 40 amplification cycles were performed in both the methylated and unmethylated tissue samples. Products were detected on $2 \%(\mathrm{w} / \mathrm{v})$ agarose gels with $100 \mathrm{bp}$ DNA markers (MBI Fermentas, Vilnius, Lithuania).

ZNF382 overexpression in GC cell lines. Lipofectamine 2000 (Invitrogen; Thermo Fisher Scientific, Inc.) was used in accordance with the instructions for the transfection of MKN45 and SGC7901 cells with $4 \mu \mathrm{g}$ pcDNA3.1- ZNF382-Flag or pcDNA3.1 plasmids (provided by Professor Qian Tao at the Chinese University of Hong Kong) in non-serum medium; $6 \mathrm{~h}$ later, the medium was replaced with fresh non-selective growth medium for $48 \mathrm{~h}$. The transfected cells were then cultured with selective medium containing G418 $(10 \mu \mathrm{l} / \mathrm{ml})$ for 14 days and the cultures were maintained with $5 \mu \mathrm{l} / \mathrm{ml} \mathrm{G} 418$. Total RNA was extracted from the cells following transfection and digested with TURBO ${ }^{\mathrm{TM}}$ DNase (Ambion, Austin, TX, USA). RT-PCR and western blot analysis were carried out to confirm the stable overexpression of ZNF382.

Immunohistochemical staining (IHC) assay. The gastric cancer tissue samples $(\mathrm{n}=55)$ were formalin-fixed and paraffinembedded. These tissue samples included 55 GC tissues and 29 matched tumor adjacent tissues. Immunohistochemical staining was then performed as previously described $(22,25)$. The sections were incubated with a rabbit monoclonal antibody (HPA049259, anti-ZNF382 antibody, 1:50 dilution; Sigma-Aldrich, St. Louis, MO, USA) at $4^{\circ} \mathrm{C}$ overnight. The following day, samples were rinsed with phosphate-buffered saline (PBS), incubated with rabbit secondary antibody (SP-9001, 1:100 dilution; ZSGB-BIO, Beijing, China) at $37^{\circ} \mathrm{C}$ for $30 \mathrm{~min}$, stained with diaminobenzidine for $33 \mathrm{sec}$, and counterstained with hematoxylin for $5 \mathrm{sec}$ to visualize the nuclei. Each section was assessed and scored by two independent pathologists who were blinded to the origin of all tissues. The widely accepted German semi-quantitative scoring criteria was used for scoring, and the staining index was determined 
Table I. List of primers used in this study.

\begin{tabular}{|c|c|c|c|c|c|}
\hline PCR & Primer & Sequence $\left(5^{\prime}-3^{\prime}\right)$ & $\begin{array}{l}\text { Product size } \\
\text { (bp) }\end{array}$ & PCR cycles & $\begin{array}{c}\text { Annealing } \\
\text { temperature }\left({ }^{\circ} \mathrm{C}\right)\end{array}$ \\
\hline \multirow[t]{14}{*}{ RT-PCR } & ZNF382F & CCTTACAGGGATCAGTGTCA & 173 & 32 & 58 \\
\hline & ZNF382R & CAACTTGCGGATCATATCAG & & & \\
\hline & SOX2F & AGCAACGGCAGCTACAGCA & 281 & & 58 \\
\hline & SOX2R & TGGGAGGAAGAGGTAACCACAG & & & \\
\hline & NANOGF & ATGAGTGTGGATCCAGCTTG & 190 & & 58 \\
\hline & NANOGR & CCTGAATAAGCAGATCCATGG & & & \\
\hline & OCT4F & AAGGAGAAGCTGGAGCAA & 303 & & 58 \\
\hline & OCT4R & GAGGGTTTCTGCTTTGCAT & & & \\
\hline & MMP2F & TTTGACGGTAAGGACGGACTC & 346 & & 58 \\
\hline & MMP2R & CCTGGAAGCGGAATGGAA & & & \\
\hline & MMP11F & TTCTTCCGAGGCAGGGACTA & 203 & & 58 \\
\hline & MMP11R & AAGCCTTCCAGAGCCTTCAC & & & \\
\hline & GAPDHF & GGAGTCAACGGATTTGGT & 206 & 23 & 58 \\
\hline & GAPDHR & GTGATGGGATTTCCATTGAT & & & \\
\hline \multirow[t]{19}{*}{ RT-qPCR } & E-cadF & TACACTGCCCAGGAGCCAGA & 103 & & 60 \\
\hline & E-cadR & TGGCACCAGTGTCCGGATTA & & & \\
\hline & VimentinF & GACCAGCTAACCAACGACAA & 150 & & 60 \\
\hline & VimentinR & GTCAACATCCTGTCTGAAAGAT & & & \\
\hline & SNAIL1F & CGCGCTCTTTCCTCGTCAG & 181 & & 60 \\
\hline & SNAIL1R & TCCCAGATGAGCATTGGCAG & & & \\
\hline & TwistF & CCACTGAAAGGAAAGGCATC & 122 & & 60 \\
\hline & TwistR & CTATGGTTTTGCAGGCCAGT & & & \\
\hline & NOTCH1F & AGGCATCCTACCCTTTTCTGG & 186 & & 60 \\
\hline & NOTCH1R & GGCTCTGGCAAGTCTCCTACAA & & & \\
\hline & NOTCH2F & AGGCAGGATTTGATGGAGTC & 150 & & \\
\hline & NOTCH2R & TCTCATGGAGGCAGAAGGAT & & & \\
\hline & NOTCH3R & CAGCAAGGCTATGGAACATG & & & \\
\hline & NOTCH4F & CTGCGATAATGCGAGGAAGATA & 144 & & 60 \\
\hline & NOTCH4R & ACGGAGTAAGGCAAGGAGGC & & & \\
\hline & HES-1F & AGATAGCTCGCGGCATTCC & 130 & & 60 \\
\hline & HES-1R & GTACTTCCCCAGCACACTTG & & & \\
\hline & JAG1F & GTGCCGCATCTCACAGCTAT & 167 & & 60 \\
\hline & JAG1R & TGATCTAAGACTGCATCACCA & & & \\
\hline \multirow[t]{4}{*}{ MSP } & ZNF382m1 & GGCGATTAACGGGTCGTTTC & 230 & 40 & 60 \\
\hline & ZNF382m2 & AAAATTTCCAAACCCGACTCG & & & \\
\hline & ZNF382U1 & GTGGTGATTAATGGGTTGTTTT & 233 & & 58 \\
\hline & ZNF382U2 & СААААТТТССАААСССААСТСА & & & \\
\hline
\end{tabular}

by multiplying the score for staining intensity with the score for staining extent, as previously described (26). Clinical data included age, sex, histological type, differentiation grade and TNM stage. Clinical follow-up data for 55 patients were censored for the analysis.

Colony formation assay. Stable MKN45 and SGC7901 cells were planted in a 6-well plate at 100 cells/well for 14 days, and the medium was refreshed every 2-3 days. The cells were fixed in $4 \%$ paraformaldehyde for $30 \mathrm{~min}$, and after staining with Gentian Violet (ICM Pharma, Singapore, Singapore) for 20 min, surviving colonies with $>50$ cells/colony were counted using Image J (V.1.8.0) software (National Institutes of Health, Bethesda, MD, USA) for the analysis. The experiments were repeated 3 times.

Cell viability. CCK-8 assay was performed according to the manufacturer's instructions (Beyotime, Shanghai, China). Stable MKN45 and SGC7901 cells were seeded in 96-well plates $\left(2 \times 10^{3}\right.$ cells/well) and cultured for 24,48 or $72 \mathrm{~h}$, and the medium in each well was then replaced with $100 \mathrm{ml}$ RPMI-1640 (10\% FBS) containing $10 \mathrm{ml} \mathrm{CCK-8} \mathrm{solution}$ and incubated at $37^{\circ} \mathrm{C}$ for $2 \mathrm{~h}$. The absorbance at $450 \mathrm{~nm}$ was measured using a microplate reader (Multiskan MK3; Thermo 
Fisher Scientific, former Fermentas, Schwerte, Germany) at 24, 48 and $72 \mathrm{~h}$. All experiments were assessed in triplicate.

Flow cytometric analysis. To investigate the cell cycle status, the cells were collected and centrifuged (200 x g for $5 \mathrm{~min})$, rinsed twice with PBS and fixed with $70 \%$ ethanol at $4^{\circ} \mathrm{C}$ overnight. The following day, the cells were treated with $50 \mathrm{mg} / \mathrm{l}$ propidium iodide (PI) (Beyotime) for $30 \mathrm{~min}$ in the condition of $4^{\circ} \mathrm{C}$ in the dark. For apoptosis analyses, the cells were washed, collected, resuspended in PBS, stained with Annexin V-FITC (BD Pharmingen, San, Jose, CA, USA) and PI, and analyzed using a flow cytometer (BD Biosciences, Franklin Lakes, NJ, USA).

Wound-healing assay. The cells were cultured in 6-well plates. Using a sterile tip to scratched a straight linear wound when the cultured cells were confluent. After rinsing with PBS, the cells were incubated with fresh growth medium. Images of the cells were captured with a 10X objective lens (Nikon, Tokyo, Japan) at 0, 24 and $48 \mathrm{~h}$ after wounding for the SGC7901 cells and at 0,12 and $24 \mathrm{~h}$ for the MKN45 cells. The experiments were performed in triplicate.

Migration and invasion assay. The migratory and invasive abilities of the GC cells were also investigated using Transwell chambers $(8 \mu \mathrm{m}$ pore size; Corning, New York, NY, USA) with or without a Matrigel (BD Biosciences) barrier added to the top chamber. The MKN45 and SGC7901 cells transfected with the ZNF382 overexpression vector or the control vector were collected, washed twice in non-serum medium, and seeded into the upper Transwell chamber. Approximately $800 \mu \mathrm{l}$ of medium with $10 \%$ FBS was added to the lower chambers. Following incubation at $37^{\circ} \mathrm{C}$ and $5 \% \mathrm{CO}_{2}$ for $24 \mathrm{~h}$, the cells were fixed in $4 \%$ paraformaldehyde for $30 \mathrm{~min}$ and stained with crystal violet (DC079; Genview, Beijing, China) for $20 \mathrm{~min}$ at room temperature. Cells on the upper side of the chamber were wiped off with a cotton bud. Cells from 6 random fields were captured and counted under a microscope (x100 magnification, CTR4000; Leica, Wetzlar, Germany).

Immunofluorescence staining. The MKN45 and SGC7901 cells were cultured in 24-well plates with glass coverslips in the wells and transiently transfected with pcDNA3.1Flag-ZNF382. Forty-eight hours later, the cells were fixed in $4 \%$ paraformaldehyde for $30 \mathrm{~min}$, then permeabilized in $0.1 \%$ Triton X-100 for $5 \mathrm{~min}$, followed by blocking with $1 \%$ bovine serum albumin (BSA) in PBS for $1 \mathrm{~h}$. The cells were then incubated with primary antibodies against ZNF382 (HPA049259, 1:200 dilution; Sigma-Aldrich) and E-cadherin (sc-8426, 1:200 dilution) or Vimentin (sc-6260, 1:200 dilution) (both from Santa Cruz Biotechnology, Inc., Santa Cruz, CA, USA) at $4^{\circ} \mathrm{C}$ overnight, then incubated with Alexa Fluor ${ }^{\circledR}$ 594-conjugated (\#A-11032, 1:200 dilution; Invitrogen; Thermo Fisher Scientific, Inc.) or FITC-conjugated (\#111-585003, 1:200 dilution; Jackson ImmunoResearch, West Grove, PA, USA) secondary antibody against rabbit or mouse IgG. 4',6-Diamidino-2-phenylindole (DAPI) was used for nuclei counterstaining. Images were captured using a confocal laser scanning microscope (x200 and x400 magnification).
Western blot analysis. This assay was conducted as previously described (27). Protein extraction reagent (Thermo Fisher Scientific, Inc.), containing phenylmethanesulfonyl fluoride, protease inhibitor and phosphatase inhibitor cocktail (Sigma-Aldrich), was used for cell lysis (all proteins were extracted from cells). Following disruption using the Ultrasonic Cell Disruptor (Ningbo Scientz Biotechnology Co., Ltd., Ningbo, China), the cell suspensions were centrifuged ( $200 \mathrm{x} \mathrm{g}$ for $4^{\circ} \mathrm{C}$ ), and the supernatant was collected. To determine the concentration of proteins, a BCA protein kit (Thermo Fisher Scientific, Inc.) was used. Sodium dodecyl sulphate/polyacrylamide gel electrophoresis was conducted for the separation of a total of $40 \mathrm{mg}$ protein lysate. Proteins were then transferred onto a polyvinylidene fluoride membrane (Bio-Rad, Hercules, CA, USA). Membranes were then incubated with blocking buffer (PBS with 5\% non-fat milk and $0.1 \%$ Tween-20) for $1 \mathrm{~h}$ at room temperature. Several primary antibodies were used: ZNF382 (HPA049259, 1:1,000 dilution; Sigma-Aldrich), E-cadherin (sc-8426, 1:1,000 dilution), Vimentin (sc-6260, 1:1,000 dilution) (both from Santa Cruz Biotechnology, Inc.), SNAIL1 (ab135708, 1:1,000 dilution; Abcam,Cambridge,UK), NOTCH1 (sc-376403, 1:1,000 dilution), NOTCH3 (sc-515825, 1:1,000 dilution), HES-1 (sc-166378, 1:1,000 dilution) and SOX2 (sc-365823, 1:1,000 dilution); GAPDH (sc-47724, 1:1,000 dilution) (all from Santa Cruz Biotechnology, Inc.) was used as a control. Anti-rabbit IgG (\#7074, 1:3,000 dilution) and anti-mouse IgG (\#7076, 1:3,000 dilution) (both from Cell Signaling Technology, Danvers, MA, USA) horseradish peroxidase conjugate secondary antibodies were used. The membranes were visualized using the enhanced chemiluminescence (ECL) detection kit (Amersham Pharmacia Biotech, Piscataway, NJ, USA).

Statistical analysis. All data were analyzed with the use of SPSS software, version 19.0 (SPSS Inc., Chicago, IL, USA). The Chi-square (also termed $\chi^{2}$ ) test was used for the analysis of the results of immunohistochemistry. The Student's t-tests, Chi-square test and Fisher's exact test were used for the comparison of the methylation status and clinicopathological characteristics of the patients with GC. For all assays, a value of $\mathrm{P}<0.05$ was considered to indicate a statistically significant difference.

\section{Results}

ZNF382 expression is downregulated in both GC cell lines and primary GC tissues. Semi-quantitative RT-PCR was carried out to examine the expression of ZNF382 in several gastric tumor cell lines and 5 normal gastric tissues. ZNF382 expression was significantly suppressed in 3 of the 5 GC cell lines, and ZNF382 was faintly expressed in the AGS and MKN28 cell lines. By contrast, ZNF382 was strongly expressed in the 5 normal gastric tissues (Fig. 2A). ZNF382 expression in the GC tissue samples and paired tumor adjacent samples was then assayed by qPCR and immunohistochemistry. A total of $55 \mathrm{GC}$ tissues and 29 matched adjacent non-tumor tissues were collected to determine the ZNF382 protein levels by immunohistochemistry. We found that ZNF382 was located predominantly in the nucleus (Fig. 1A). The majority of the tumor tissue samples (51/55) had a lower level of ZNF382, while the adjacent non-tumor samples (21/29) exhibited 

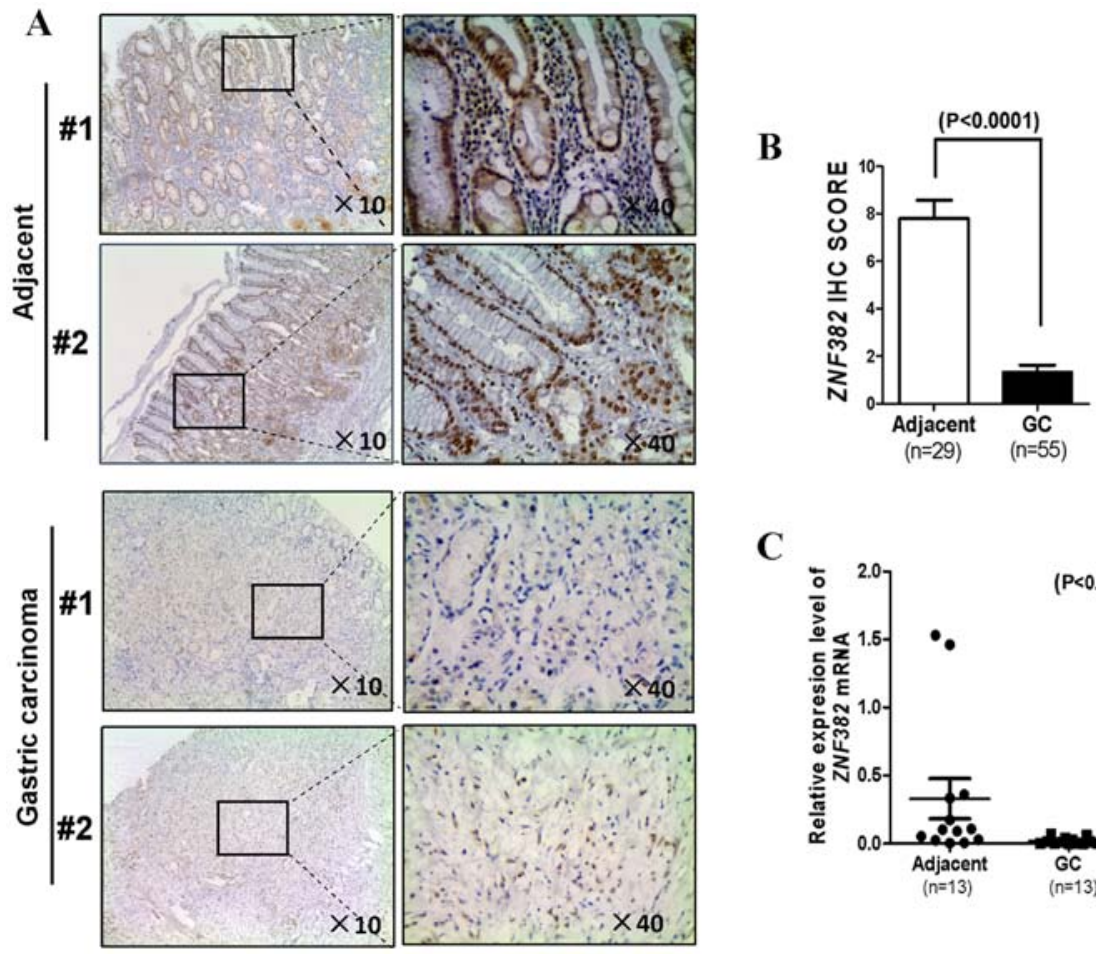

C

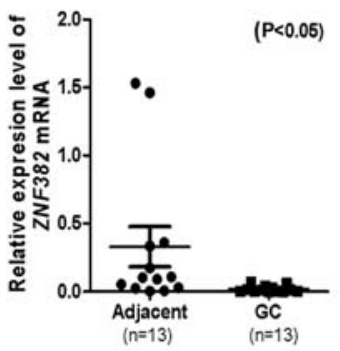

Figure 1. Expression levels of ZNF382 in gastric tumor tissues and adjacent non-tumor tissues. (A) Representative images of ZNF382 immunohistochemical staining in paired gastric tumor and adjacent non-tumor tissues (adjacent tissues, high ZNF382 expression in the majority of adjacent non-tumor samples; carcinoma tissues, low ZNF382 expression in the majority of the samples). (B) Differences in the ZNF382 immunohistochemical staining score in paired gastric tumor and adjacent non-tumor tissues $(\mathrm{P}<0.001)$. (C) mRNA expression levels of ZNF382 in human gastric tumor and adjacent non-tumor tissues were detected by qPCR ( $\mathrm{P}<0.05)$. GC, gastric cancer tissues.

a higher ZNF382 level $(\mathrm{P}<0.0001)$ (Fig. 1B). The mRNA expression level of ZNF382 in 13 additional GC samples was markedly decreased in comparison with the paired tumor adjacent tissues $(\mathrm{P}<0.05)$ (Fig. 1C). These findings indicated that ZNF382 expression was downregulated in both GC cells and primary GC tissues. No association was observed between the ZNF382 expression level and the clinicopathological characteristics of the patients with GC (Table II).

ZNF382 downregulation in $G C$ cell lines by promoter $C p G$ methylation. We then determined whether promoter $\mathrm{CpG}$ methylation is the primary cause for the downregulation of ZNF382 in GC cell lines. The ZNF382 promoter methylation status in $4 \mathrm{GC}$ cell lines was detected with the use of MSP. The hypermethylation of the ZNF382 promoter was observed in 3 of the 4 gastric tumor cell lines (Fig. 2A). To examine whether ZNF382 suppression was due directly to promoter methylation, we treated the MKN45 and SGC7901 cells with Aza and TSA, and then performed RT-PCR. The restoration of ZNF382 expression was observed following treatment with Aza and TSA (Fig. 2B).

We further assayed the methylation of the ZNF382 promoter in $70 \mathrm{GC}$ tissues, as well as 22 matched adjacent non-tumor gastric tissues. The results revealed that ZNF382 was methylated in 100\% (70/70) of primary GC tissues (Figs. 2C and 3), and the methylation level was significantly higher in the majority of the GC tissues compared with the adjacent nontumor tissues (Fig. 3). However, we failed to identify any inter-relation between ZNF382 promoter methylation and the patient clinicopathological characteristics (data not shown).
Table II. Association between the clinicopathological characteristics of the patients with gastric cancer and ZNF382 expression.

\begin{tabular}{lrrrrrr}
\hline & \multicolumn{5}{c}{ ZNF382 expression } & \\
\cline { 3 - 5 } Parameter & No. None Low & Moderate & High & P-value \\
\hline Sex & & & & & & 0.283 \\
$\quad$ Female & 15 & 5 & 10 & 0 & 0 & \\
$\quad$ Male & 40 & 20 & 16 & 2 & 2 & \\
Age (years) & & & & & & 0.504 \\
$\quad \leq 60$ & 28 & 13 & 14 & 1 & 0 & \\
$>60$ & 27 & 13 & 11 & 1 & 2 & \\
Tumor size (cm) & & & & & & 0.668 \\
$\leq 3$ & 12 & 6 & 5 & 1 & 0 & \\
$>3$ & 43 & 20 & 20 & 1 & 2 & \\
Metastasis & & & & & & 0.731 \\
$\quad$ None & 37 & 17 & 17 & 2 & 1 & \\
$\quad$ Yes & 18 & 9 & 8 & 0 & 1 & \\
Grade & & & & & & 0.793 \\
$\quad$ G2 & 14 & 6 & 7 & 1 & 0 & \\
G3 & 41 & 20 & 17 & 2 & 2 & \\
T Stage & & & & & & 0.714 \\
$\quad$ Ta-T2 & 8 & 3 & 5 & 0 & 0 & \\
T3-T4 & 47 & 24 & 20 & 2 & 1 & \\
\hline P-ves & & &
\end{tabular}

P-values were calculated using the $\chi^{2}$ test. 


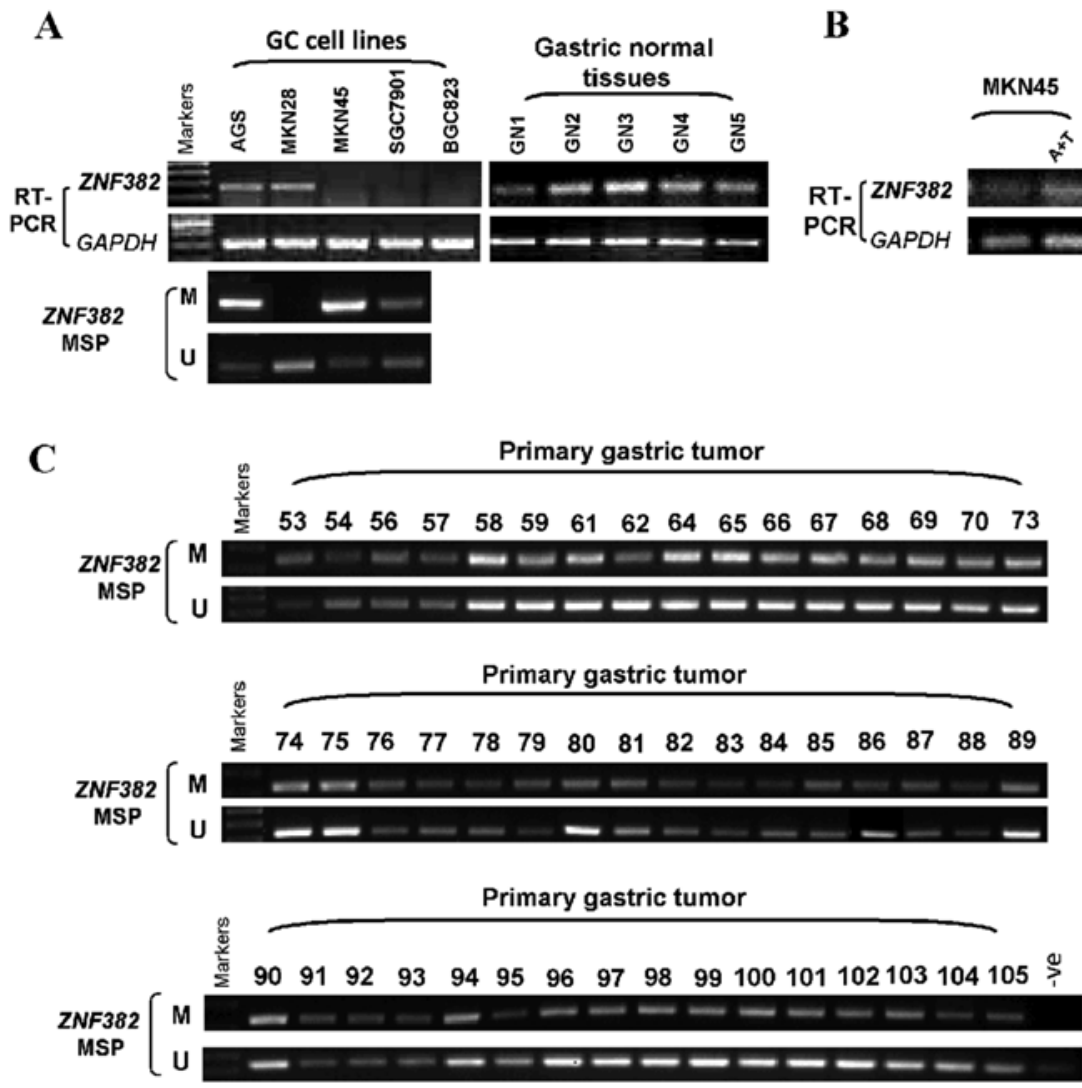

Figure 2. Methylation status of the ZNF382 promoter in gastric cancer cell lines and primary tumor tissues. (A) Expression levels of ZNF382 in gastric cancer cells and normal tissues and promoter methylation of ZNF382 in gastric cancer cells. 'M' indicates methylated ZNF382, and ' $U$ ' indicates unmethylated ZNF382. (B) Restoration of ZNF382 expression by 5-aza-2'-deoxycytidine (Aza) with trichostatin A (TSA) treatment of the MKN45 and SGC7901 cells (C) Methylation of ZNF382 in gastric cancer as measured by methylation-specific PCR (MSP).
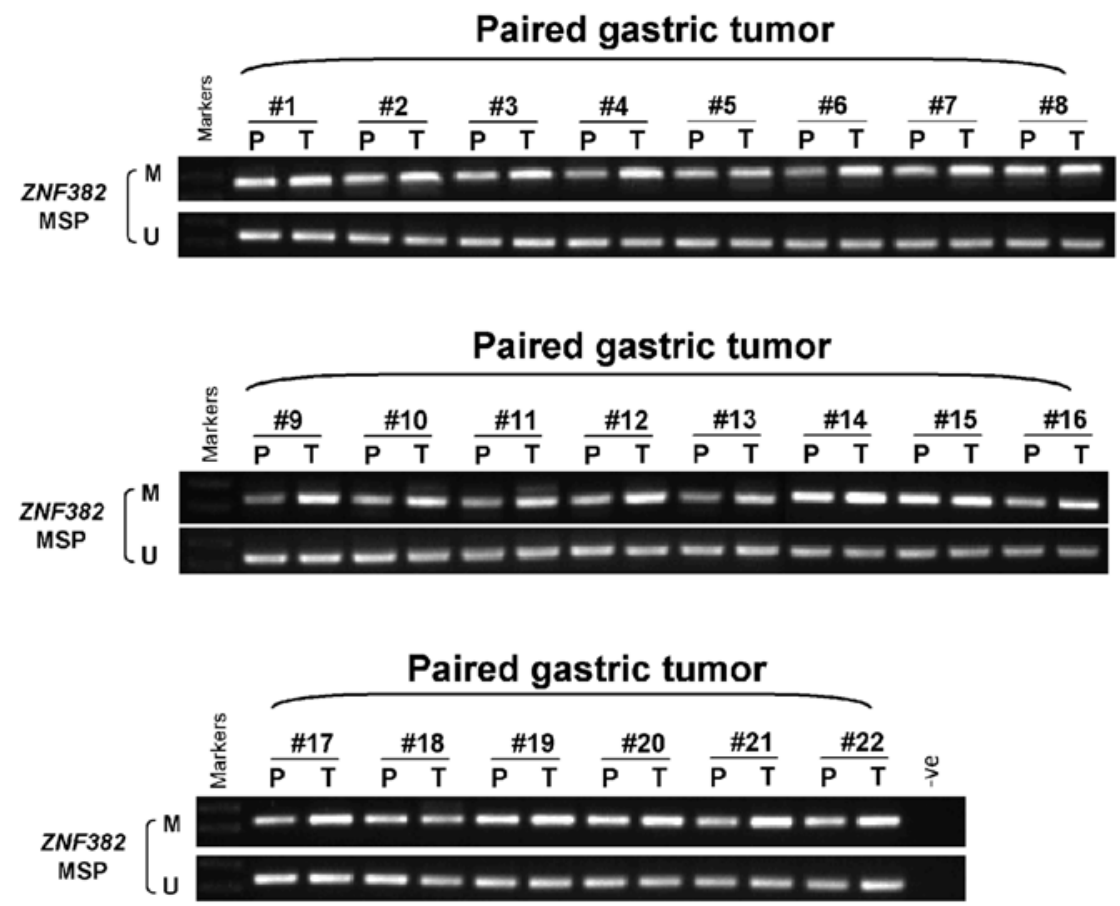

Figure 3. Methylation status of the ZNF382 promoter in paired gastric tumor tissues and their adjacent non-tumor tissues. 'M' indicates methylated ZNF382; ' $\mathrm{U}$ ' indicates unmethylated ZNF382; ' $\mathrm{T}$ ' indicates gastric cancer tissues; and ' $\mathrm{P}$ ' indicates paired adjacent non-tumor tissues.

ZNF382 inhibits colony formation and proliferation, and induces cell cycle arrest and the apoptosis of GC cell lines.
Several methods were used to determine the function of ZNF382 in GC cells. To investigate whether ZNF382 affects 


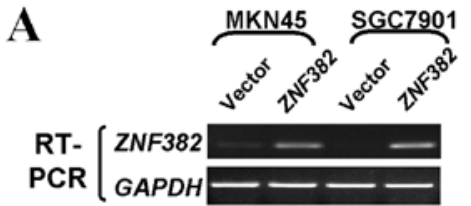

C
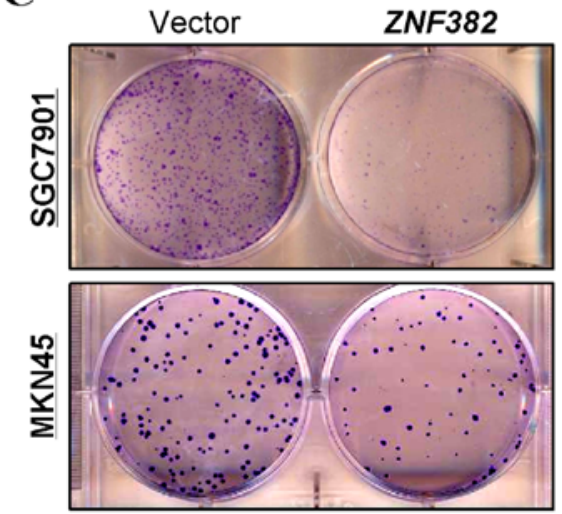

$\mathbf{E}$

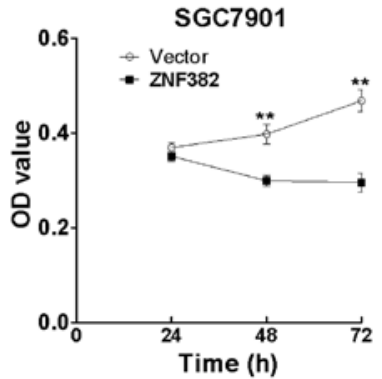

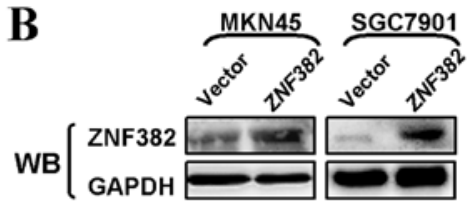

D
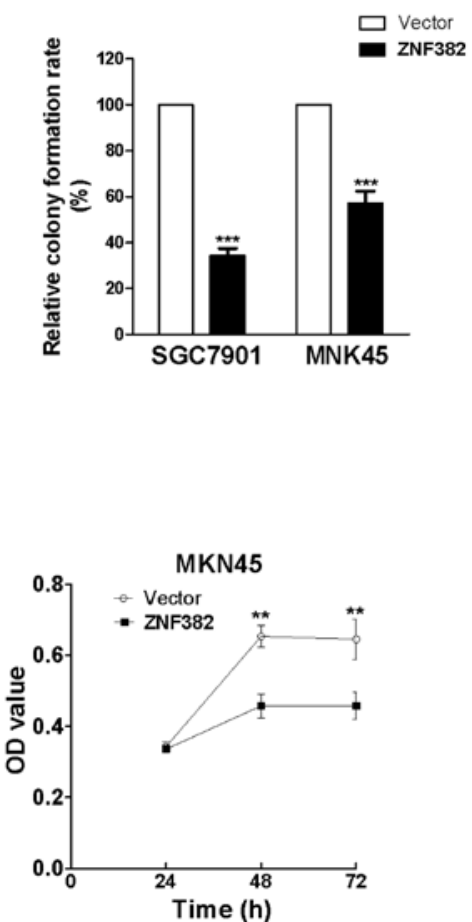

Figure 4. Inhibitory effect of ZNF382 in gastric cancer. (A and B) The expression of ZNF382 was confirmed by RT-PCR and western blot analysis in the MKN45 and SGC7901 cells transfected with the control vector or the ZNF382 overexpression vector. (C) Representative images of colony formation assay in the MKN45 and SGC7901 cells transfected with the control vector or the ZNF382 overexpression vector. (D) Quantitative analysis of colony formation. The values were shown as the means \pm SD from 3 independent experiments $\left({ }^{* * *} \mathrm{P}<0.001\right)$. (E) Measurement of cell proliferation of the MKN45 and SGC7901 cells transfected with the control vector or the $Z N F 382$ overexpression vector by CCK- 8 assay $\left({ }^{* *} \mathrm{P}<0.01\right)$.

cell growth in GC, colony formation and CCK8 assays were carried out using stably transfected MKN45 and SGC7901 cells. ZNF382 expression in the cell lines was verified by RT-PCR and western blot analysis (Fig. 4A and B). The ectopic expression of ZNF382 markedly reduced the ability of the GC cells to form colonies compared with the controls $(\mathrm{P}<0.001)$ (Fig. 4C and D). Cell viability also decreased markedly at 48 and $72 \mathrm{~h}(\mathrm{P}<0.01)$ (Fig. 4E).

In addition, flow cytometry was used to determine whether ZNF382 affects the cell cycle and apoptosis of GC cells. It was found that a greater number of ZNF382-expressing cells had accumulated in the G0/G1 phase of the cell cycle compared with the controls $(\mathrm{P}<0.001)$ (Fig. 5A). Subsequently, Annexin V-FITC/PI staining assay was performed to assess the rate of apoptosis. We found that ZNF382 exerted a proapoptotic effect on these two GC cell lines $(\mathrm{P}<0.05$ and $\mathrm{P}<0.01$ ) (Fig. 5B), suggesting that ZNF382 acts as a potential tumor suppressor in GC.

ZNF382 suppresses cell migration and invasion in gastric tumor cells. The effects of ZNF382 on the migration and invasion of GC cells were investigated using wound-healing and Transwell assays. The results of wound-healing assay revealed that ZNF382-expressing SGC7901 cells were less able to migrate along the edges of wounds at 24 and $48 \mathrm{~h}$ compared with the controls, while the same phenomenon was observed in the MKN45 cells at 12 and $24 \mathrm{~h}(\mathrm{P}<0.001)$ (Fig. 6A and B). Furthermore, the results of Transwell assay illustrated that the number of migrated cells was markedly decreased in the ZNF382-transfected cells compared with the controls $(\mathrm{P}<0.001)$ (Fig. 6C and D). In the Transwell assay, which included a Matrigel barrier, ZNF382 overexpression was associated with the inhibition of GC cell invasion through the Matrigel before traversing the Transwell chamber membrane $(\mathrm{P}<0.05, \mathrm{P}<0.001)$ (Fig. $6 \mathrm{E}$ and $\mathrm{F}$ ), indicating that ZNF382 inhibits the migration and invasion of GC cells.

ZNF382 can reverse EMT through NOTCH signaling in GC cells. We then examined whether ZNF382 can affect EMT in GC cells. The results indicated that ectopic ZNF382 expression reversed EMT to mesenchymal-to-epithelial transition in both cell lines examined (MKN45 and SGC7901). The 
A
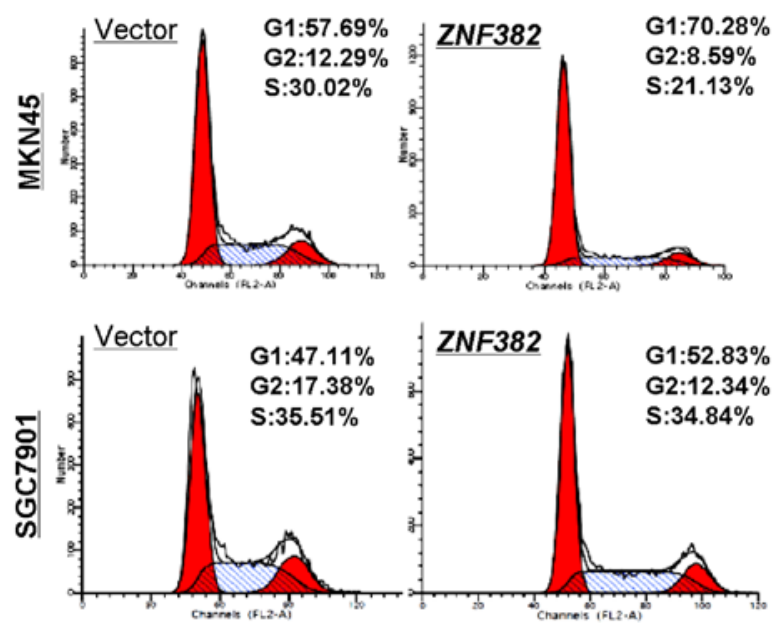

B
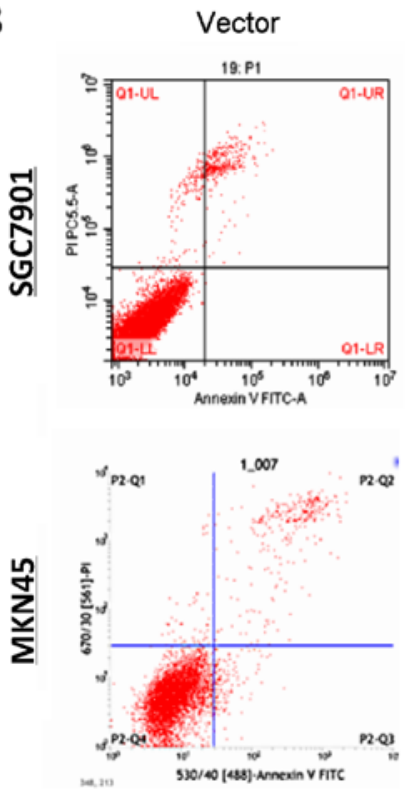

ZNF382
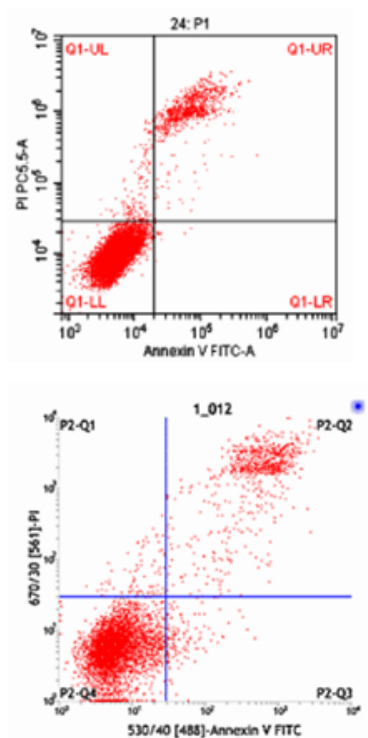
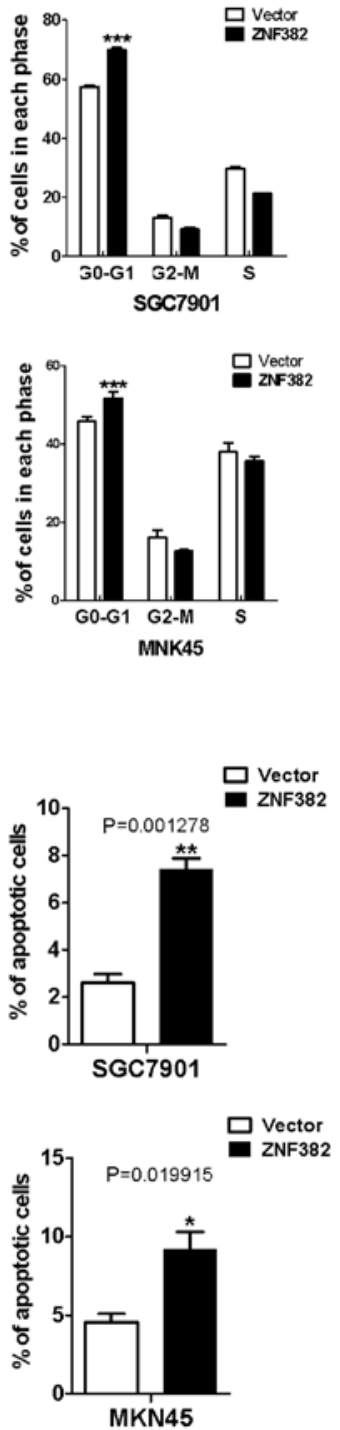

Figure 5. Flow cytometric analysis. (A) Cell cycle distribution in the MKN45 and SGC7901 cells transfected with the control vector or the ZNF382 overexpression vector detected by flow cytometry analyses. Representative images of cell cycle distribution (left panels) and statistical graphs of cell cycle changes (right panels) $\left({ }^{* * *} \mathrm{P}<0.001\right)$. (B) Apoptosis of the MKN45 and SGC7901 cells transfected with the control vector or the ZNF382 overexpression vector detected by Annexin V-FITC/PI staining ( $\left(\mathrm{P}<0.05\right.$ and $\left.{ }^{* *} \mathrm{P}<0.01\right)$.

results of western blot analysis and qPCR confirmed that E-cadherin expression was increased in the cells transfected with ZNF382, and the expression of SNAIL1, Twist and Vimentin was decreased (Fig. 7A-C). Moreover, immunofluorescence revealed increased staining for E-cadherin and decreased staining for Vimentin in the ZNF382-expressing cells (Fig. 7D), indicating that ZNF382 suppressed EMT in GC cells.

Recent studies have illustrated that NOTCH signaling plays a role in promoting EMT in multiple carcinoma types (14,16-18). In this study, we thus examined whether ZNF382 is related to this pathway. The results of RT-PCR and $\mathrm{qPCR}$ revealed that the ectopic expression of ZNF382 downregulated the important receptor and ligand markers of the NOTCH signaling pathway (e.g., NOTCH1, NOTCH2, NOTCH3, NOTCH4 and JAG1) in the MKN45 and SGC7901 cells (Fig. 8A-C). The results were verified by western blot analysis, revealing that the NOTCH signaling downstream target, HES-1, was also downregulated in ZNF382-expressing cells (Fig. 8D). Thus, these findings suggest that ZNF382 reverses the EMT process by antagonizing NOTCH signaling, although this requires further investigation.

Finally, cells that have stem-like properties are tightly connected with EMT in tumor cells. Thus, we investigated whether ZNF382 suppresses stemness in GC cells. Several markers of cell stemness, such as NANOG, octamer-binding transcription factor 4 (OCT4) and SOX2, were downregulated in ZNF382-expressing cells (Fig. 8A-C). These results were confirmed by western blot analysis (Fig. 8D), illustrating that ZNF382 suppresses both EMT and stemness in GC cells.

\section{Discussion}

Previous research has revealed that ZNF382 is commonly silenced by the methylation of its promoter, and that ZNF382 exists in multiple carcinoma types, including colorectal, 
A
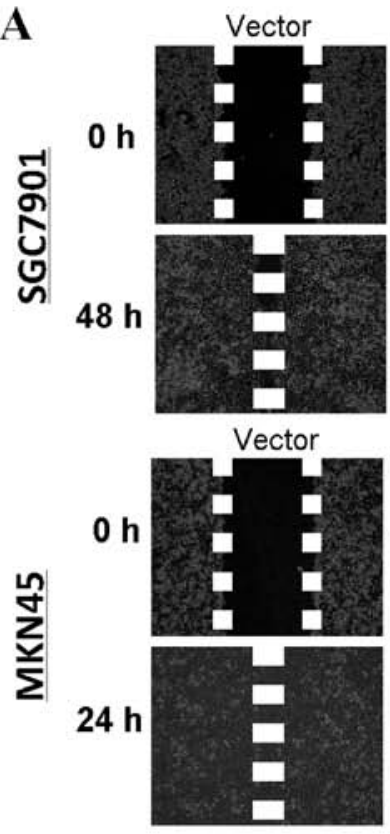

C

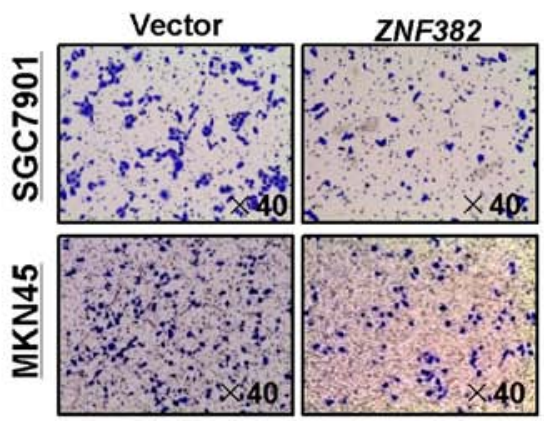

E
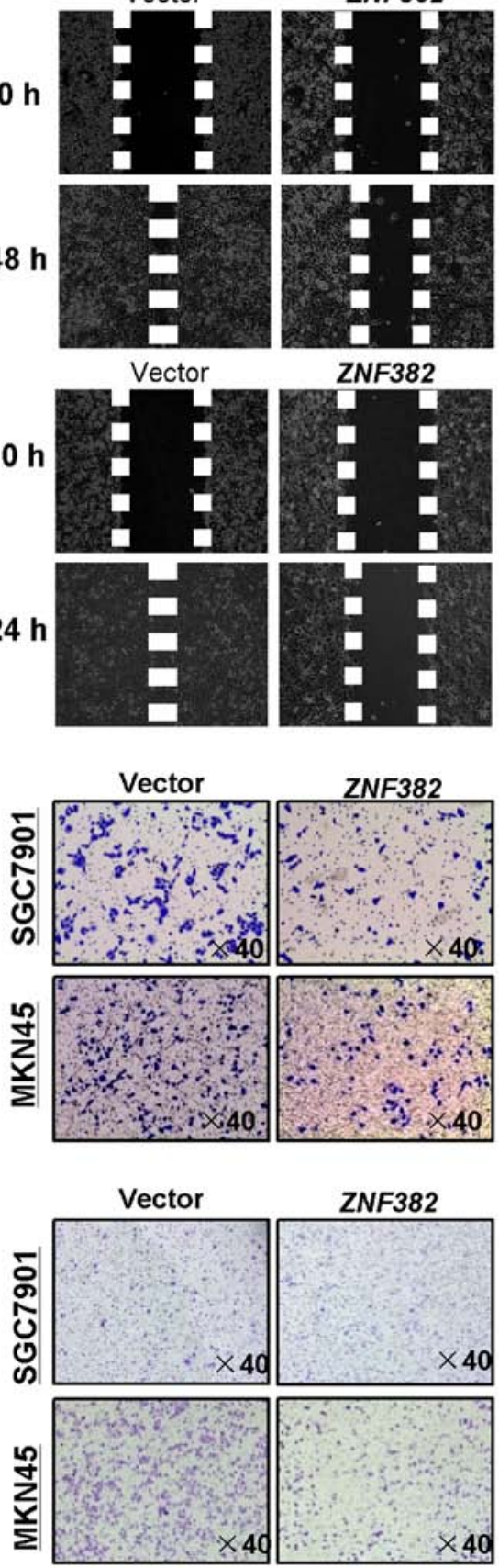
ZNF382

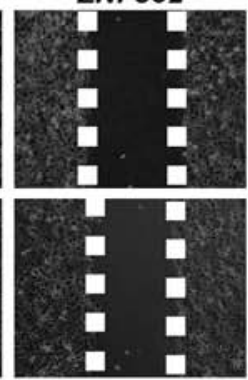

B

D

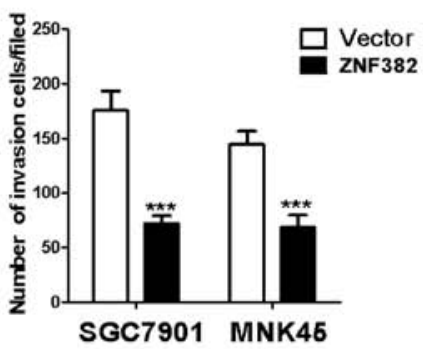

F

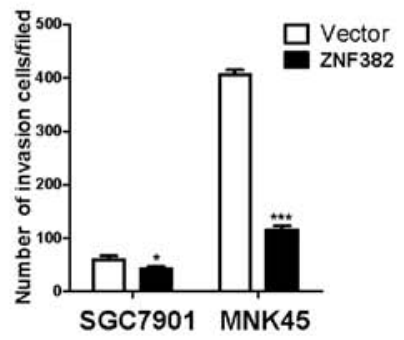

Figure 6. Ectopic expression of ZNF382 inhibits the migration and invasion of gastric cancer cells. (A and B) The cellular migration abilities (MKN45 and SGC7901) were examined by wound healing assays. Images were captured at 0,24 or $48 \mathrm{~h}$. The ratio of wound healing was calculated (right panels) $\left.{ }^{(* * *} \mathrm{P}<0.001\right)$. (C-F) ZNF382 inhibited the migration and invasion of the gastric carcinoma cells, $\mathrm{x} 400$ magnification $\left({ }^{*} \mathrm{P}<0.05\right.$ and $\left.{ }^{* * *} \mathrm{P}<0.001\right)$. Each experiment was performed 3 times.

nasopharyngeal, gastric and breast carcinomas as a tumor suppressor (9). However, as a novel member of the KRAB-ZFP family, little is known about its role in GC. Thus, it is worth elucidating the direct association between ZNF382 and GC. In this study, we observed that ZNF382 expression was decreased in several GC cell lines and GC tissues. We also noted that ZNF382 expression was decreased in the AGS and MKN28 cells, while it was silent in the BGC823, MKN45 and SGC7901 cells. MSP and demethylation treatment revealed that the downregulation of ZNF382 in the GC cell lines and GC tumors was a result of promoter methylation. We then examined the tumor-repressive function of ZNF382 in the MKN45 and SGC7901 cells. The ectopic expression of ZNF382 in these two cell lines markedly repressed clonogenicity, suppressed cell proliferation, restrained migration and invasion, and induced apoptosis; these data illustrate that ZNF382 functions as a tumor suppressor in GC cells.

Moreover, ZNF382 binds to target promoters and acts as a transcriptional repressor. Therefore, investigating the target genes affected by ZNF382 may prove to be pivotal for revealing the underlying mechanisms of its suppressive effect. As such, RT-PCR and qPCR assays were carried out to screen the downstream target genes of ZNF382. Our results revealed that the ectopic expression of ZNF382 significantly reversed EMT 

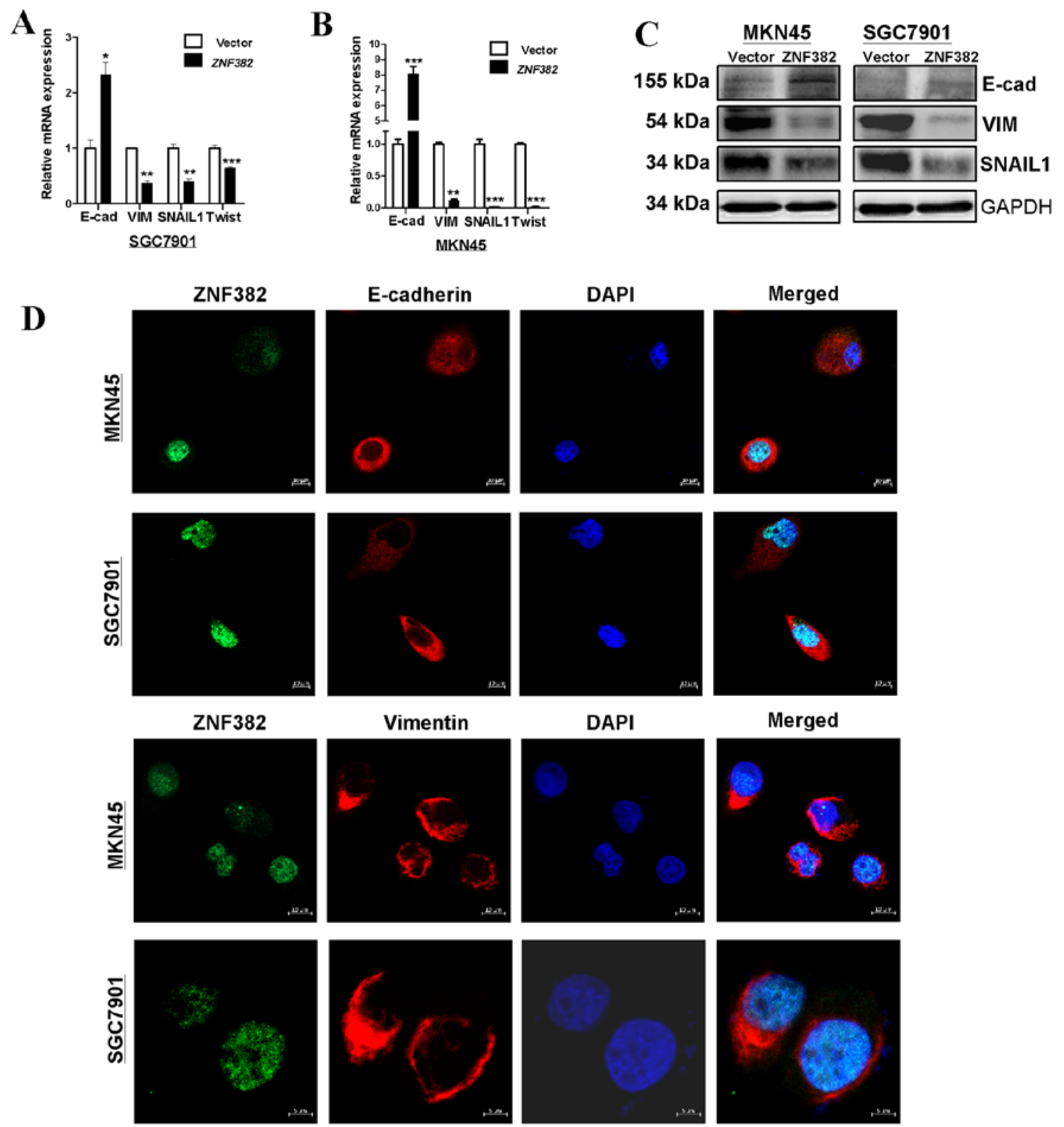

Figure 7. Effects of ZNF382 on epithelial-mesenchymal transition (EMT) in gastric cancer cells. (A and B) mRNA expression levels of Vimentin (VIM), E-cadherin (E-cad), SNAIL1 and Twist were examined by qPCR in the MKN45 and SGC7901 cells ( ${ }^{*} \mathrm{P}<0.05,{ }^{* *} \mathrm{P}<0.01$ and $\left.{ }^{* * *} \mathrm{P}<0.001\right)$. (C) Western blot analyses of EMT and its downstream target markers. (D) Immunofluorescence staining of ZNF382 with E-cadherin and Vimentin in MKN45 and SGC7901 cells.

to a mesenchymal-to-epithelial transition in both the MKN45 and SGC7901 cells, evidenced by the increased expression of the epithelial marker, E-cadherin, and the decreased expression of the mesenchymal markers, Vimentin, SNAIL1 and Twist. These findings indicate that ZNF382 may serve as a transcriptional repressor, reversing EMT in GC cells.

$\mathrm{NOTCH}$ is bound by its ligands, which is followed by the cleavage and release of the NOTCH intracellular domain (NICD). NICD regulates downstream target genes by translocating to the nucleus and binding specific transcriptional regulators $(12,28)$. As recently reported, the NOTCH signaling pathway promotes EMT in multiple carcinoma types, including GC $(12,14)$. However, it remains unclear as to whether ZNF382 is associated with the NOTCH signaling pathway in GC. RT-PCR and qPCR assays revealed that the ectopic expression of $\mathrm{ZNF} 382$ downregulated the expression of NOTCH1, NOTCH2, NOTCH3, NOTCH4, HES-1 and JAG1, as well as that of several stem cell markers (OCT4, SOX2 and $N A N O G)$. Some of these results were confirmed by western blot analysis, which indicated that ZNF382 overexpression downregulates NOTCH1, NOTCH3 and its downstream target, HES-1, in the MKN45 and SGC7901 cells. Thus, we hypothesized that ZNF382 may reverse EMT by antagonizing NOTCH signaling; however, further investigations are required to determine the exact mechanisms through which ZNF382 regulates EMT via NOTCH signaling. Moreover, further studies such as sphere forming assay are warranted to determine whether ZNF382 suppresses stemness properties.

In conclusion, we found that promoter methylation is a key mechanism contributing to the downregulation of ZNF382 in GC cells. We further confirmed that ZNF382 is a functional TSG in GC by inducing cell apoptosis and suppressing tumor cell growth and metastasis and may be considered as a tumor marker for GC. 
A

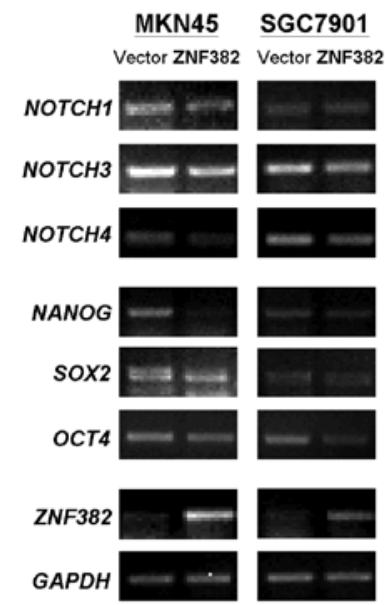

D

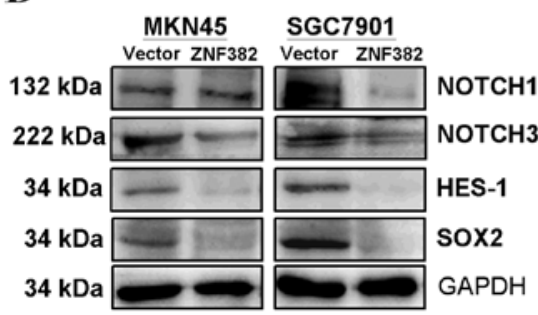

B

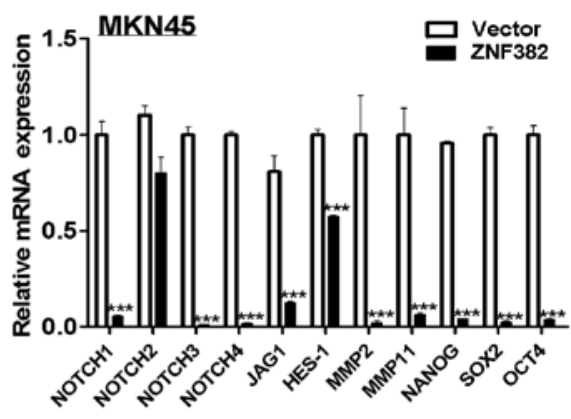

C

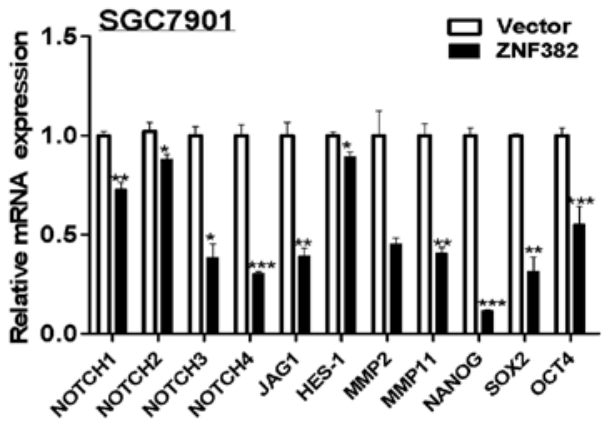

Figure 8. Ectopic expression of ZNF382 in MKN45 and SGC7901 cells disrupted NOTCH signaling and stem cell markers. (A-C) Representative stem cell markers and NOTCH signaling were detected in the MKN45 and SGC7901 cells transfected with the control vector or the ZNF382 overexpression vector by RT-PCR or q-PCR $\left({ }^{*} \mathrm{P}<0.05,{ }^{* *} \mathrm{P}<0.01\right.$ and $\left.{ }^{* * *} \mathrm{P}<0.001\right)$. (D) Examination of NOTCH and its target, HES-1, and the stem cell marker, SOX2, by western blot analysis.

\section{Acknowledgements}

The authors would like to thank Professor Qian Tao (the Chinese University of Hong Kong, Hong Kong, China) for providing some cell lines, primers and plasmids.

\section{Funding}

This study was supported by grants from the Science Foundation of Health Planning Committee of Chongqing (no. 2016ZDXM006) and National Natural Science Foundation of China (no. 81572769).

\section{Availability of data and materials}

All data generated or analyzed during this study are included in this published article.

\section{Authors' contributions}

TX and GR made substantial contributions to the conception and design of the study. LP, SL, XH and RS performed the experiments and analyzed the data; QX was involved in the acquisition of the samples and the interpretation of the data for the study; LP and TX prepared the figures and drafted the manuscript; TX and LP revised the study critically for important intellectual content; TX and GR finalized the manuscript. All authors have read and approved the final manuscript.

\section{Ethics approval and consent to participate}

This study was approved by the Ethics Committee of the First Affiliated Hospital of Chongqing Medical University, and all patients provided signed informed consent.

\section{Patient consent for publication}

Not applicable.

\section{Competing interests}

The authors declare that they have no competing interests.

\section{References}

1. Riquelme I, Letelier P, Riffo-Campos AL, Brebi P and Roa JC: Emerging role of miRNAs in the drug resistance of gastric cancer. Int J Mol Sci 17: 424, 2016.

2. Catalano V, Labianca R, Beretta GD, Gatta G, de Braud F and Van Cutsem E: Gastric cancer. Crit Rev Oncol Hematol 71: 127-164, 2009.

3. Van Cutsem E, Sagaert X, Topal B, Haustermans K and Prenen H: Gastric cancer. Lancet 388: 2654-2664, 2016.

4. Urrutia R: KRAB-containing zinc-finger repressor proteins. Genome Biol 4: 231, 2003.

5. Gebelein B, Fernandez-Zapico M, Imoto $M$ and Urrutia R: KRAB-independent suppression of neoplastic cell growth by the novel zinc finger transcription factor KS1. J Clin Invest 102: 1911-1919, 1998.

6. Knight RD and Shimeld SM: Identification of conserved $\mathrm{C} 2 \mathrm{H} 2$ zinc-finger gene families in the Bilateria. Genome Biol 2: RESEARCHO016, 2001. 
7. Cowger JJ, Zhao Q, Isovic $\mathrm{M}$ and Torchia J: Biochemical characterization of the zinc-finger protein 217 transcriptional repressor complex: Identification of a ZNF217 consensus recognition sequence. Oncogene 26: 3378-3386, 2007.

8. Huntley S, Baggott DM, Hamilton AT, Tran-Gyamfi M, Yang S, Kim J, Gordon L, Branscomb E and Stubbs L: A comprehensive catalog of human KRAB-associated zinc finger genes: Insights into the evolutionary history of a large family of transcriptional repressors. Genome Res 16: 669-677, 2006.

9. Cheng Y, Geng H, Cheng SH, Liang P, Bai Y, Li J, Srivastava G, $\mathrm{Ng} \mathrm{MH}$, Fukagawa T, Wu X, et al: KRAB zinc finger protein ZNF382 is a proapoptotic tumor suppressor that represses multiple oncogenes and is commonly silenced in multiple carcinomas. Cancer Res 70: 6516-6526, 2010.

10. Kalluri R and Weinberg RA: The basics of epithelial-mesenchymal transition. J Clin Invest 119: 1420-1428, 2009.

11. Fan Y, Wang YF, Su HF, Fang N, Zou C, Li WF and Fei ZH: Decreased expression of the long noncoding RNA LINC00261 indicate poor prognosis in gastric cancer and suppress gastric cancer metastasis by affecting the epithelial-mesenchymal transition. J Hematol Oncol 9: 57, 2016.

12. Zang M, Zhang B, Zhang Y, Li J, Su L, Zhu Z, Gu Q, Liu B and Yan M: CEACAM6 promotes gastric cancer invasion and metastasis by inducing epithelial-mesenchymal transition via PI3K/AKT signaling pathway. PLoS One 9: e112908, 2014.

13. Shimokawa M,Haraguchi M,Kobayashi W,Higashi Y,Matsushita S, Kawai K, Kanekura T and Ozawa M: The transcription factor Snai expressed in cutaneous squamous cell carcinoma induces epithelialmesenchymal transition and down-regulates COX-2. Biochem Biophys Res Commun 430: 1078-1082, 2013.

14. Colas E, Pedrola N, Devis L, Ertekin T, Campoy I, Martínez E, Llauradó M, Rigau M, Olivan M, Garcia M, et al: The EMT signaling pathways in endometrial carcinoma. Clin Trans Oncol 14: 715-720, 2012.

15. Chen W, Zhang H, Wang J, Cao G, Dong Z, Su H, Zhou X and Zhang S: Lentiviral-mediated gene silencing of Notch-4 inhibits in vitro proliferation and perineural invasion of ACC-M cells Oncol Rep 29: 1797-1804, 2013.

16. Fender AW, Nutter JM, Fitzgerald TL, Bertrand FE and Sigounas G: Notch-1 promotes stemness and epithelial to mesenchymal transition in colorectal cancer. J Cell Biochem 116: 2517-2527, 2015.

17. Kostina AS, Uspensky VE, Irtyuga OB, Ignatieva EV, Freylikhman O, Gavriliuk ND, Moiseeva OM,Zhuk S, Tomilin A, Kostareva AA, et al: Notch-dependent EMT is attenuated in patients with aortic aneurysm and bicuspid aortic valve. Biochim Biophys Acta 1862: 733-740, 2016.

18. Yuan X, Wu H, Han N, Xu H, Chu Q, Yu S, Chen Y and Wu K: Notch signaling and EMT in non-small cell lung cancer: Biological significance and therapeutic application. J Hematol Oncol 7: 87, 2014 .
19. Zhang Y,Xu M,Zhang X, Chu F and Zhou T: MAPK/c-Jun signaling pathway contributes to the upregulation of the anti-apoptotic proteins Bcl-2 and Bcl-xL induced by Epstein-Barr virus-encoded BARF1 in gastric carcinoma cells. Oncol Lett 15: 7537-7544, 2018.

20. Capes-Davis A, Theodosopoulos G, Atkin I, Drexler HG, Kohara A, MacLeod RA, Masters JR, Nakamura Y, Reid YA, Reddel RR, et al: Check your cultures! A list of cross-contaminated or misidentified cell lines. Int J Cancer 127: 1-8, 2010

21. Ying J, Li H, Seng TJ, Langford C, Srivastava G, Tsao SW, Putti T, Murray P, Chan AT and Tao Q: Functional epigenetics identifies a protocadherin PCDH10 as a candidate tumor suppressor for nasopharyngeal, esophageal and multiple other carcinomas with frequent methylation. Oncogene 25: 1070-1080, 2006.

22. Xiang T, Li L, Yin X, Yuan C, Tan C, Su X, Xiong L, Putti TC, Oberst M, Kelly K, et al: The ubiquitin peptidase UCHL1 induces G0/G1 cell cycle arrest and apoptosis through stabilizing p53 and is frequently silenced in breast cancer. PLoS One 7: e29783, 2012.

23. Tao Q, Huang H, Geiman TM, Lim CY, Fu L, Qiu GH and Robertson KD: Defective de novo methylation of viral and cellular DNA sequences in ICF syndrome cells. Hum Mol Genet 11: 2091-2102, 2002.

24. Tao Q, Swinnen LJ, Yang J, Srivastava G, Robertson KD and Ambinder RF: Methylation status of the Epstein-Barr virus major latent promoter $\mathrm{C}$ in iatrogenic $\mathrm{B}$ cell lymphoproliferative disease. Application of PCR-based analysis. Am J Pathol 155: 619-625, 1999.

25. Mu H, Wang N, Zhao L, Li S, Li Q, Chen L, Luo X, Qiu Z, Li L, Ren G, et al: Methylation of PLCD1 and adenovirus-mediated PLCD1 overexpression elicits a gene therapy effect on human breast cancer. Exp Cell Res 332: 179-189, 2015.

26. Pan X, Zhou T, Tai YH, Wang C, Zhao J, Cao Y, Chen Y, Zhang PJ, Yu M, Zhen C, et al: Elevated expression of CUEDC2 protein confers endocrine resistance in breast cancer. Nat Med 17: 708-714, 2011.

27. Yin X, Xiang T, Li L, Su X, Shu X, Luo X, Huang J, Yuan Y, Peng W, Oberst M, et al: DACT1, an antagonist to Wnt/ $\beta$-catenin signaling, suppresses tumor cell growth and is frequently silenced in breast cancer. Breast Cancer Res 15: R23, 2013.

28. Güngör C, Zander H, Effenberger KE, Vashist YK, Kalinina T, Izbicki JR, Yekebas E and Bockhorn M: Notch signaling activated by replication stress-induced expression of midkine drives epithelial-mesenchymal transition and chemoresistance in pancreatic cancer. Cancer Res 71: 5009-5019, 2011.

This work is licensed under a Creative Commons Attribution-NonCommercial-NoDerivatives 4.0 International (CC BY-NC-ND 4.0) License. 